\title{
ADIÇÃO DO PÓ DE DESPOEIRAMENTO DA FABRICAÇÃO DE FERRO LIGAS DE MANGANÊS E EFEITOS NA FABRICAÇÃO DE CERÂMICA*
}

Tiany Guedes Cota ${ }^{1}$ Leticia Maria de Melo Silva Cheloni² Amanda Cristina Gonçalves Silva ${ }^{2}$ Almiro Santana Junior ${ }^{3}$ Érica Linhares Reis ${ }^{4}$ Carlos Alberto Pereira ${ }^{5}$

\section{Resumo}

A indústria cerâmica utiliza as argilas como matéria-prima para fabricação de cerâmica vermelha, branca, de material refratário, entre outros. Possuem um vasto campo de aplicação devido às suas características que, em geral, são decorrentes de sua composição química e do processo de fabricação que lhe originou, tais como: temperatura de queima, proporção dos componentes e granulometria da matéria-prima utilizadas. Comumente vem sendo realizada a substituição de parte da massa argilosa por resíduos industriais, para aproveitamento de materiais, diminuição de custos e impacto ambiental. Nesse presente trabalho, foi realizado um planejamento fatorial em dois níveis das variáveis de adição de pó, temperatura de queima e pressão de compactação nas propriedades de densidade, retração linear de secagem (RLS) e de queima (RLQ). A coloração final também foi um parâmetro analisado. A temperatura parece ser a variável que mais influenciou nos resultados de densidade e RLQ. A pressão de compactação dos corpos de prova não foi uma variável significativa na densidade, RLS e RLQ. Logo, a condição ótima para fabricação dos corpos cerâmicos foi com incorporação de $10 \%$ de pó de despoeiramento em substituição ao solo argiloso e temperatura de queima de $1000^{\circ} \mathrm{C}$.

Palavras-chave: Argila; Resíduo de manganês; Cerâmica.

\section{ADITTION OF DEDUSTING POWDER OF MANGANESE FERROALLOY MANUFACTURE AND EFFECTS ON CERAMIC MANUFACTURING}

\section{Abstract}

The ceramics industry uses clay as raw material for the manufacture of red ceramic, white ceramic, refractory material, among others. They have a wide field of application due to its characteristics, in general, are due to its chemical composition and manufacturing process that led to it, such as firing temperature, the proportion of components and particle size of the raw material used. Commonly it is being held to replace part of the clayey mass by industrial waste, for recovery materials, to reduce costs and environmental impact. In this present study, we performed a factorial design at two levels of addition of powder variables, firing temperature and compaction pressure on density properties, linear retraction drying (LRD) and linear retraction burning (LRB). The final coloring was also a parameter analyzed. The temperature seems to be the variable that most influenced the results of density and LRB. The pressure compression of the specimens was not a significant variable in density, LRD and LRB. Therefore, the optimal condition for the production of ceramic specimens incorporating $10 \%$ dedusting powder in replacement of clayey soil and $1000^{\circ} \mathrm{C}$ firing temperature.

Keywords: Clay; Manganese residue; Ceramic.

1 Mestranda em Engenharia Mineral, Programa de Pós Graduação em Engenharia Mineral, Universidade Federal de Ouro Preto (UFOP), Ouro Preto, Minas Gerais, Brasil.

Graduanda em Engenharia Metalúrgica, UFOP, Ouro Preto, MG, Brasil.

Graduando em Engenharia de Minas, UFOP, Ouro Preto, Minas Gerais, Brasil.

Professora Doutora, Departamento de Engenharia de Minas, UFOP, Ouro Preto, MG, Brasil.

Professor Doutor, Departamento de Engenharia de Minas, UFOP, Ouro Preto, MG, Brasil. 


\section{INTRODUÇÃO}

A aplicação dos materiais cerâmicos é extremamente ampla devido às suas características, sendo cada vez mais utilizados no âmbito da engenharia. [1] Em geral, essas características são decorrentes de sua composição química e do processo de fabricação que Ihe originou, tais como: temperatura de queima, proporção dos componentes e granulometria da matéria-prima utilizadas. [2]

$\mathrm{Na}$ fabricação desses materiais, propriedades como cor, densidade, retração linear de secagem (RLS) e retração linear de queima (RLQ) são determinantes para qualidade final do produto, sendo indesejáveis defeitos como trincas e porosidade. As colorações da cerâmica podem variar de avermelhadas até grafite escuro de acordo com Santos [3]. A densidade do compacto pode ser influenciada por fatores como umidade, pressão de prensagem e das reações que ocorrem durante a queima, impactando as propriedades finais da peça. [4]

Vem sendo comum a produção de cerâmicas com substituição de parte do solo argiloso por resíduos de diversas áreas, minimizando a quantidade de massa argilosa consumida e, portanto, o custo da matéria-prima para produção da cerâmica. Consequentemente, levando a uma economia de recursos minerais. [5]

Santos [3] estudou a incorporação de um pó de despoeiramento gerado na fabricação de ligas de manganês fornecido pela empresa Vale Manganês situada no município de Simões Filho, Bahia. Segundo o autor, são necessárias 2,25 toneladas de minério para produção de 1 tonelada de liga e que o processo gera resíduos em torno de $5 \%$ dessa quantidade de minério. O autor conclui que a incorporação deste resíduo a massa argilosa mostrou-se viável do ponto de vista técnico até um limite máximo de $10 \%$, sendo também o material classificado como não perigoso e inerte.

Segundo avaliação da produção da usina de fabricação de ferro-ligas de manganês em estudo, o processo gera, em média, $70 \mathrm{~kg}$ de pó de despoeiramento para cada tonelada de ferro liga produzida. [6]

O objetivo deste trabalho é avaliar o efeito da incorporação do pó de despoeiramento da fabricação de ferro ligas de manganês em corpos de prova cerâmico dosados em diferentes proporções, nas propriedades de cor, densidade, retração linear de secagem e de queima.

\section{MATERIAIS E MÉTODOS}

O solo utilizado neste trabalho foi caracterizado por Ferreira [7], sendo que pela técnica de difração de raios-X (DRX) foram identificados os seguintes minerais: quartzo $\left(\mathrm{SiO}_{2}\right)$, caulinita $\left(\mathrm{SiO}_{2} \mathrm{Al}_{2} \mathrm{O}_{5}(\mathrm{OH})_{4}\right)$ e muscovita $\left(\mathrm{KAl}_{2}\left(\mathrm{Si}_{3} \mathrm{Al}\right) \mathrm{O}_{10}(\mathrm{OH})_{2}\right)$. Cerca de $70 \%$ do material está abaixo de $74 \mu \mathrm{m}$.

O pó de despoeiramento foi proveniente de uma usina de fabricação de ferro ligas de manganês localizada no estado de Minas Gerais e caracterizado por Oliveira [6], apresentando os minerais franklinita $\left((\mathrm{Zn}, \mathrm{Mn}, \mathrm{Fe})_{2} \mathrm{O}_{4}\right)$, e dolomita $\left(\mathrm{CaMg}\left(\mathrm{CO}_{3}\right)_{2}\right)$, podendo estar presentes fases metálicas não identificadas por concentrações abaixo do limite de detecção do equipamento ou modo de interpretação do software do equipamento de difração. Cerca de $80 \%$ do pó está abaixo de $1,60 \mu \mathrm{m}$.

Os ensaios foram efetuados segundo planejamento estatístico de experimentos. $O$ planejamento fatorial de experimentos foi realizado em dois níveis e três variáveis, com o auxílio do software estatístico minitab. Considerando as variáveis, pressão de compactação $(P)$, temperatura de queima $(T)$, e porcentagem de substituição de solo por pó de despoeiramento da fabricação de ferro ligas de manganês (AP). Sendo 
que estas foram variadas em níveis máximos e mínimos e os testes realizados em duplicata, conforme apresentado na Tabela 1.

Tabela 1. Planejamento fatorial dos experimentos dos corpos de prova cerâmicos variando: substituição de solo por pó de despoeiramento, temperatura de queima e pressão de compactação

\begin{tabular}{ccccc}
\hline Testes & Ordem & Temperatura $\left({ }^{\circ} \mathrm{C}\right)$ & Pressão $(\mathrm{MPa})$ & Adição de pó $(\%)$ \\
\hline 1 & 3 & 750 & 40 & 5 \\
\hline 2 & 14 & 1000 & 20 & 10 \\
\hline 3 & 11 & 750 & 40 & 5 \\
\hline 4 & 1 & 750 & 20 & 5 \\
\hline 5 & 15 & 750 & 40 & 10 \\
\hline 6 & 8 & 1000 & 40 & 10 \\
\hline 7 & 2 & 1000 & 20 & 5 \\
\hline 8 & 12 & 1000 & 40 & 5 \\
\hline 9 & 10 & 1000 & 20 & 5 \\
\hline 10 & 4 & 1000 & 40 & 10 \\
\hline 11 & 16 & 1000 & 40 & 10 \\
\hline 12 & 6 & 1000 & 20 & 10 \\
\hline 13 & 5 & 750 & 20 & 10 \\
\hline 14 & 13 & 750 & 20 & 5 \\
\hline 15 & 7 & 750 & 40 &
\end{tabular}

A construção dos corpos de prova cerâmicos com substituição de solo argiloso por pó de despoeiramento seguiu as etapas apresentadas na Figura 1. 


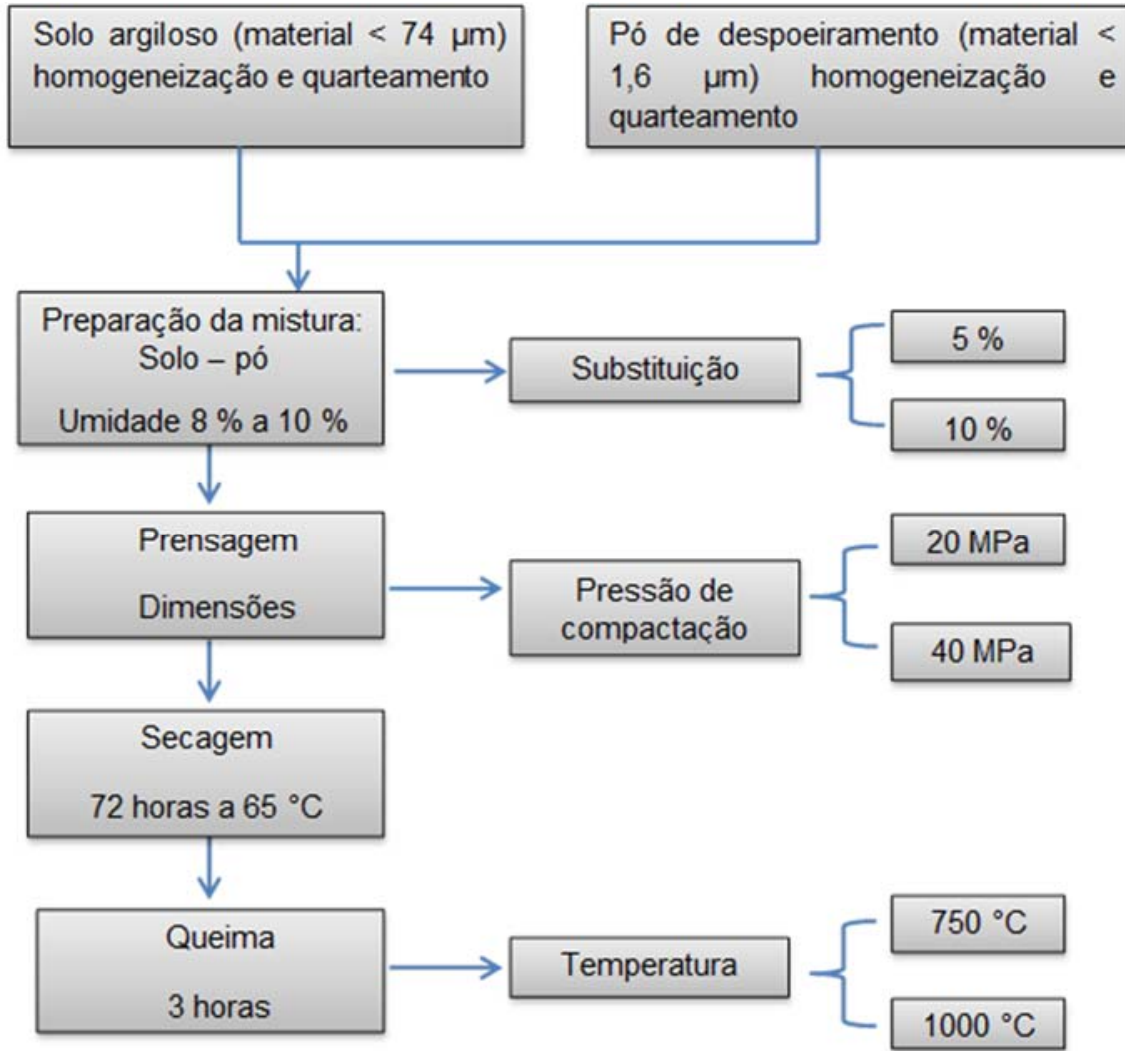

Figura 1. Etapas da construção dos corpos de prova de cerâmica com substituição do solo argiloso por pó de despoeiramento da fabricação de ferro ligas de manganês.

As massas necessárias foram pesadas utilizando uma balança analítica da marca.... e também foi medida a umidade do material utilizando balança analítica Marte ID200. Foi utilizada prensa Cl100 toneladas-força, marca SOLOCAP. As dimensões dos corpos de prova foram medidas com o auxílio de um paquímetro após as etapas de prensagem, secagem e queima. De posse desses valores, foi possível calcular a densidade aparente, a retração linear de secagem e de queima de cada corpo de prova.

\section{RESULTADOS E DISCUSSÃO}

De acordo com os resultados, nota-se que o maior valor para densidade resultante das interações é igual a $1,84 \mathrm{~g} / \mathrm{cm}^{3}$ e é obtida na condição de adição de $10 \%$ pó e temperatura de $1000^{\circ} \mathrm{C}$. Isto provavelmente pelo fato do pó ser mais denso do que o solo, e uma maior temperatura de queima.

A figura 2 indica que as combinações de maiores valores de densidade são quando se alinham maiores valores de temperatura e adição de pó. 


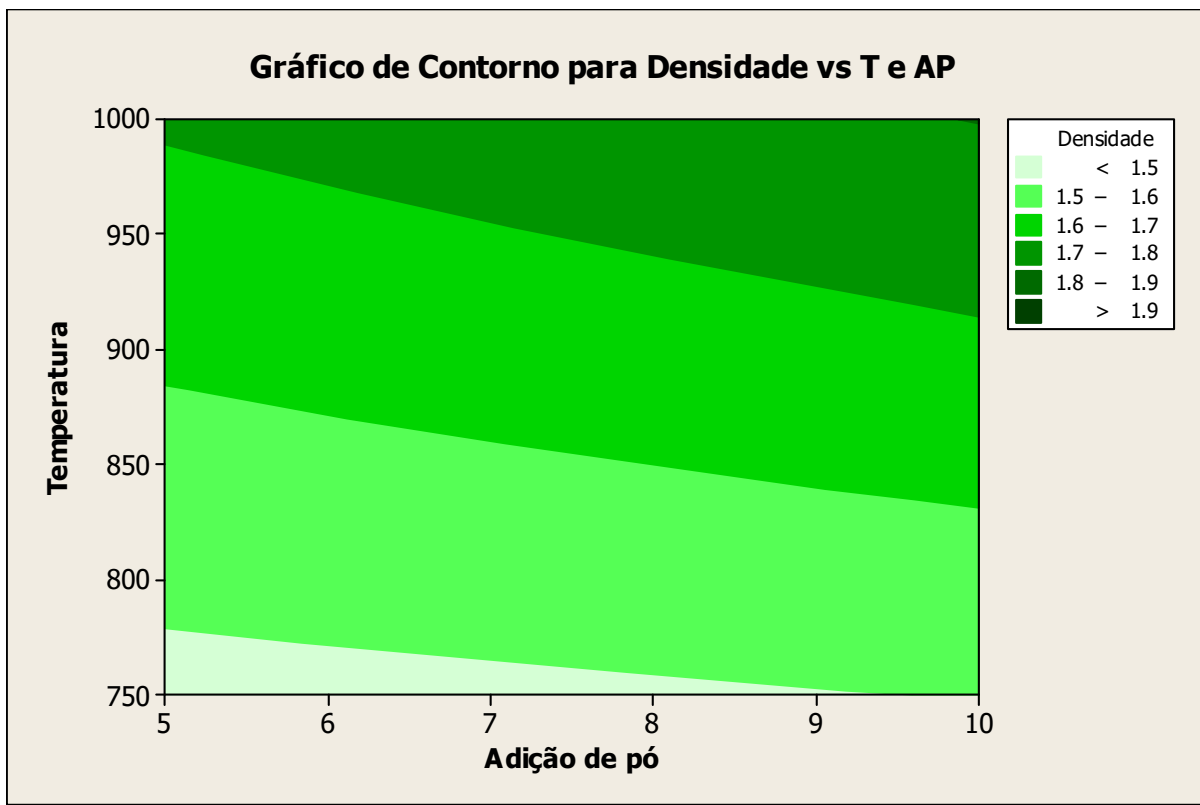

Figura 2. Gráfico de contorno para densidade vs T,AP.

As figuras 3 e 4 mostram as relações entre as variáveis pressão e composição na propriedade retração linear de secagem.

A figura 3 mostra que as duas variáveis afetaram a propriedade RLS, considerando que a retração diminui com o aumento da pressão, porém aumenta com uma maior adição de pó.

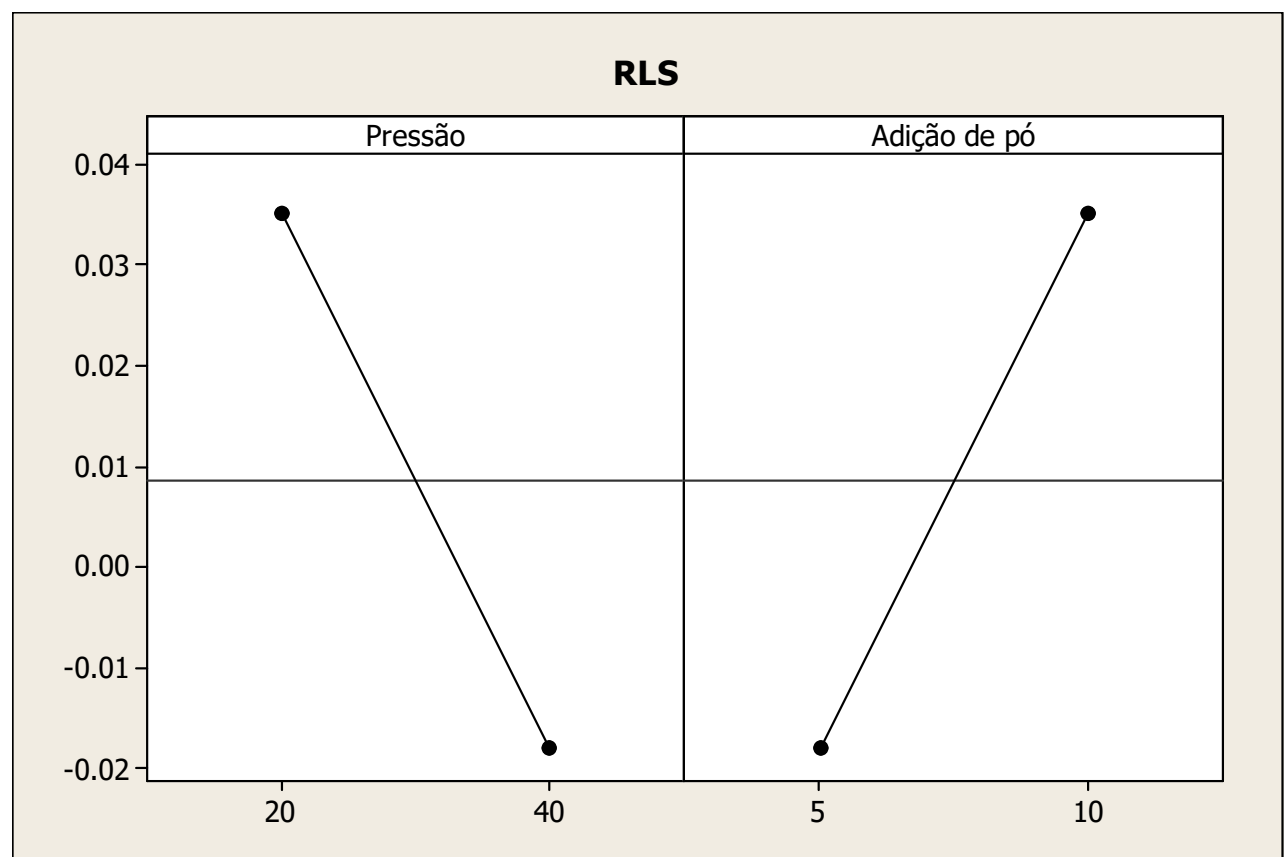

Figura 3. Gráfico do efeito das variáveis na RLS.

A figura 4 indica que em maiores valores de pressão houve uma pequena expansão, provavelmente devido a uma recuperação elástica na retirada do corpo de prova do molde. Segundo Oliveira [8], para evitar problemas de "trincas" e pequenas fissuras localizadas nas bordas das peças é conveniente manter as variações dimensionais na fase de secagem a valores compreendidos entre 0 e $0,3 \%$ no máximo. Por isso, o ideal seria associar valores intermediários de pressão e adição de pó, para se trabalhar com retrações nulas. 


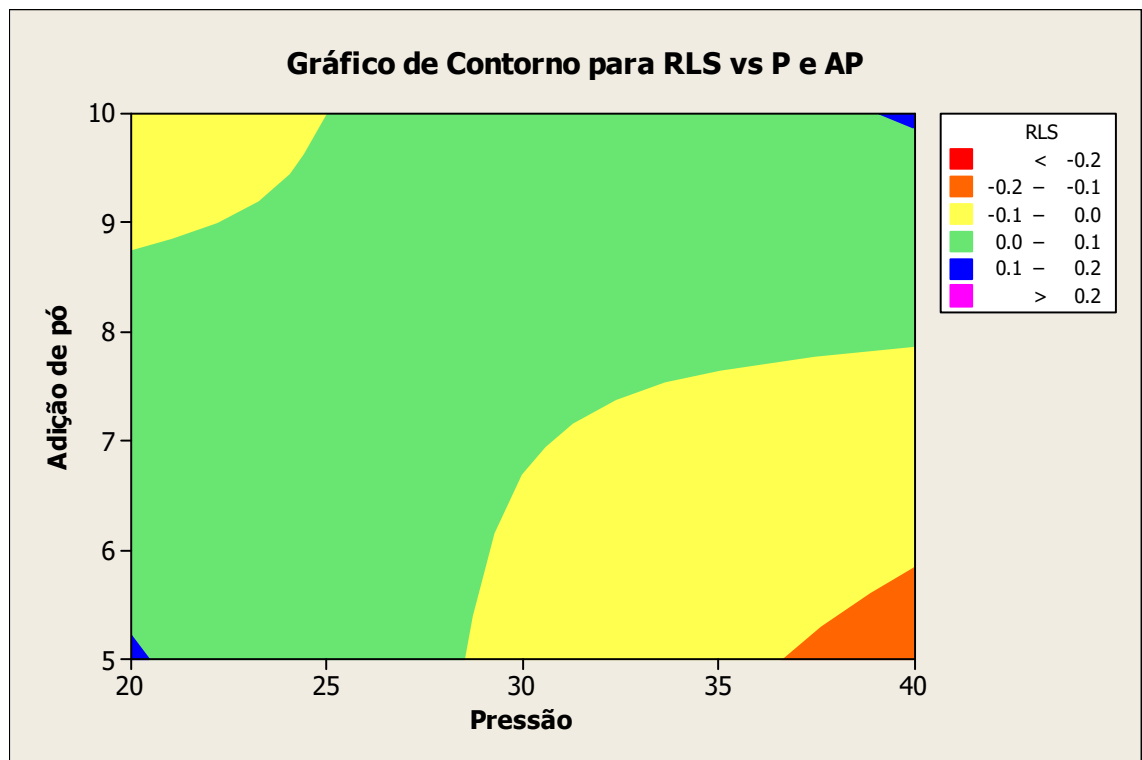

Figura 4. Gráfico de contorno para RLS vs P e AP

Outro fator importante na etapa de secagem é que a água está distribuída entre as partículas de argila e outros componentes. Esta água precisa ser retirada cuidadosamente e de forma homogênea, já que a sua saída aproxima as partículas, diminuindo o tamanho da peça. Se essa diminuição não for uniforme também poderá provocar trincas ou, em casos extremos a quebra da peça). [9]

As figuras 5 e 6 mostram as relações entre as variáveis temperatura, pressão e adição de pó na propriedade retração de queima.

Pela análise da figura 5 nota-se que o maior valor para RLQ resultante de interações é igual a $5,5285 \%$ e foi devido a combinação de adição de pó de $10 \%$, pressão de $40 \mathrm{MPa}$ e temperatura de queima de $1000^{\circ} \mathrm{C}$. Conforme Acchar [10], o valor total de retração não deve exceder $12 \%$, sob risco do aparecimento de trincas no produto final. Quanto maior a RLQ, maior será a densificação do corpo cerâmico. Uma maior densificação provocará a diminuição da porosidade, resultando em menor absorção de água e uma tendência a maior resistência mecânica. [11]

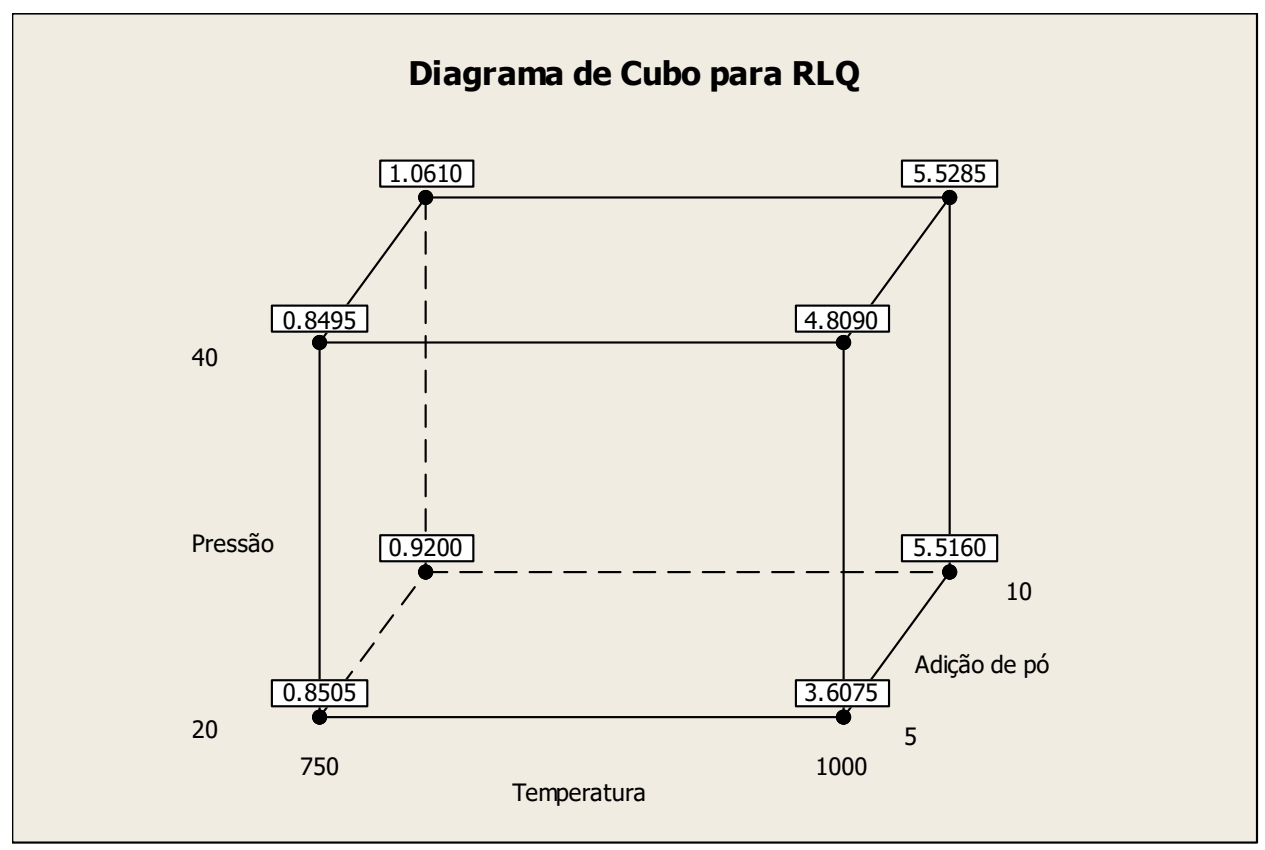

Figura 5. Diagrama de cubo para RLQ. 
A figura 6 apresenta a temperatura como variável de maior efeito na RLQ uma vez que a inclinação da reta é maior do que as demais. Já a variável pressão teve a menor influência nos resultados.

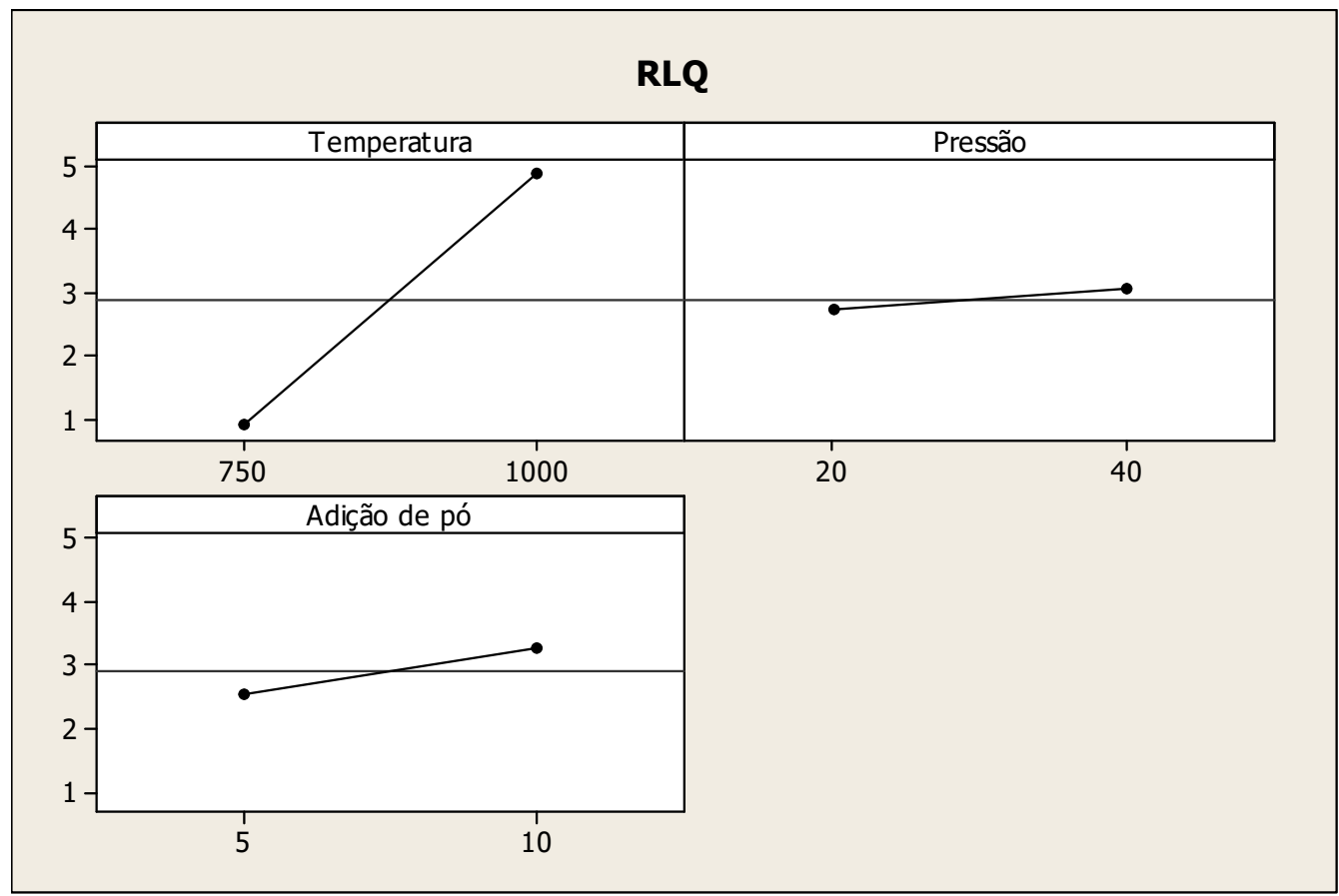

Figura 6. Gráfico do efeito das variáveis na RLQ.

Foi possível observar que quanto maior a substituição de pó, maior foi a retração de queima, isso provavelmente está associado à formação da fase líquida pelo solo que migra pelos interstícios formados pelas partes refratárias, levando a aproximação das partes e uma maior retração.

A condição ótima para fabricação dos corpos cerâmicos do trabalho parece ser a com adição de pó de $10 \%$, temperatura de queima de $1000^{\circ} \mathrm{C}$ e pressão de compactação com valores entre 20MPa e 40MPa.

As colorações dos corpos de prova antes e após a queima a $750^{\circ} \mathrm{C}$ e $1000^{\circ} \mathrm{C}$ estão apresentadas nas figuras 7,8 e 9 .

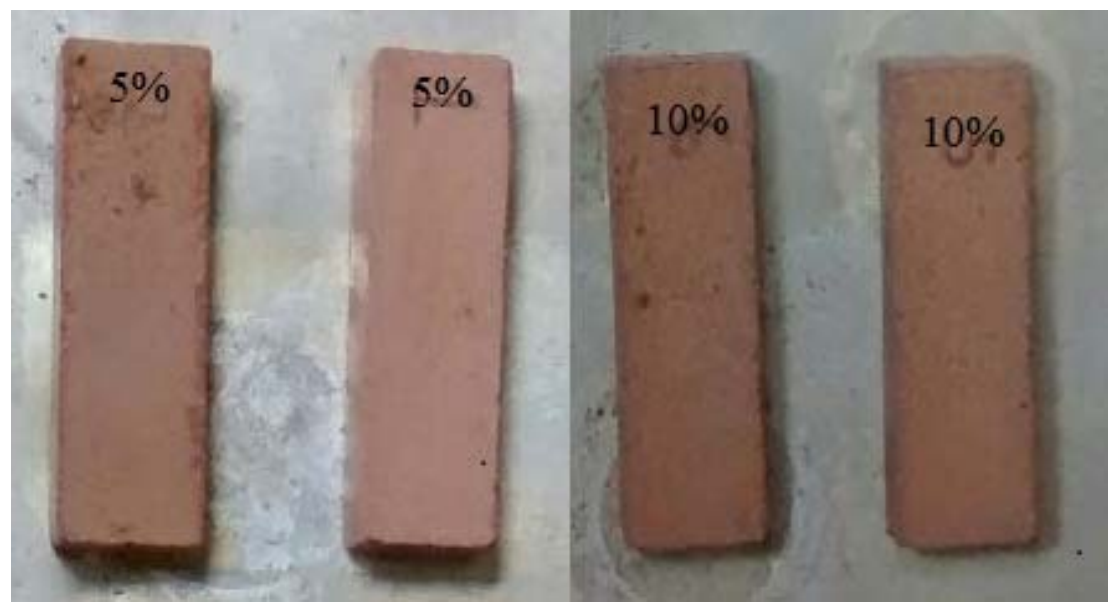

Figura 7. Corpos de prova antes da queima.

Dimensões estimadas dos corpos de prova:7x2x1 cm 

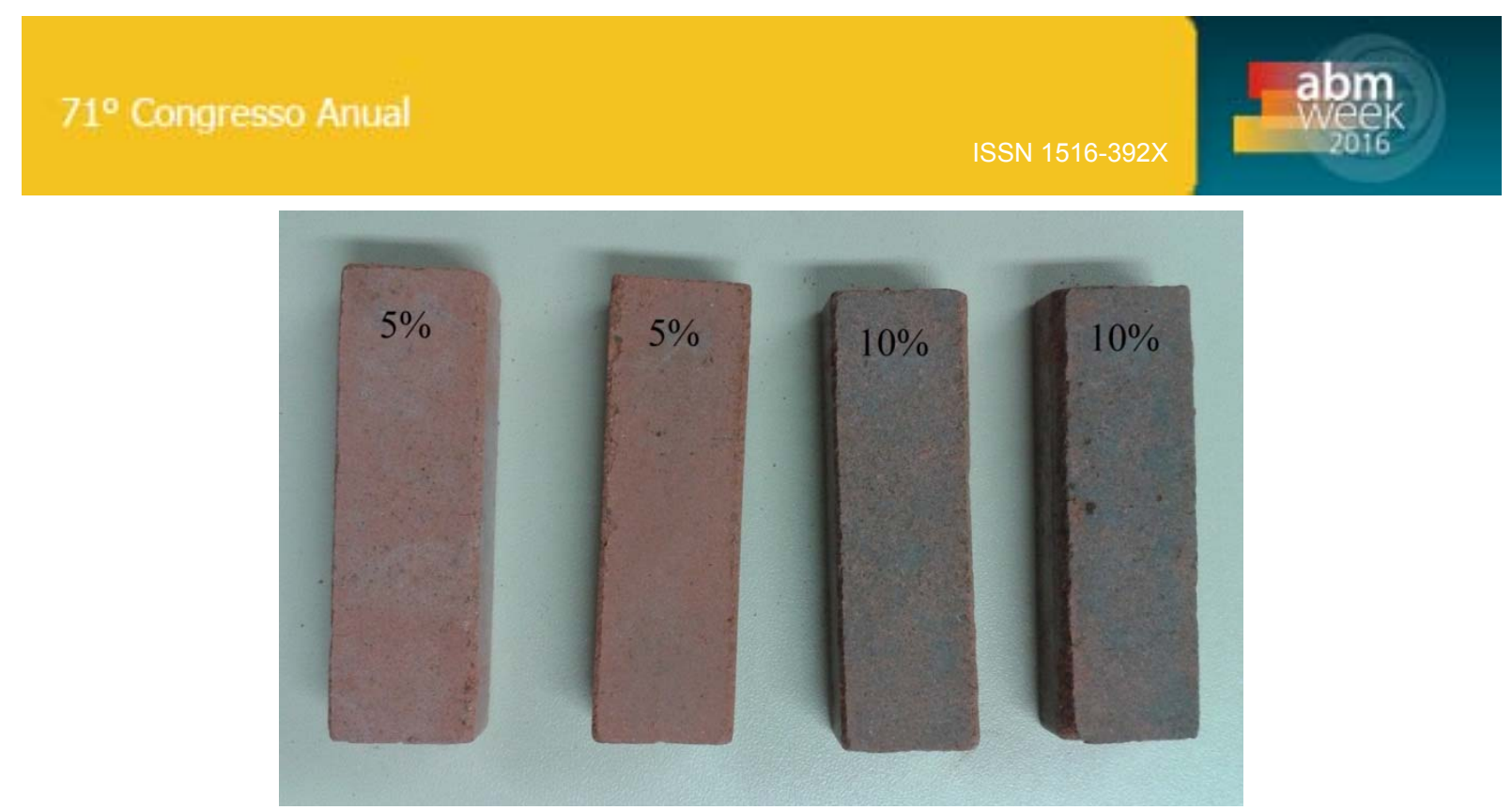

Figura 8. Corpos de prova depois da queima a $750^{\circ} \mathrm{C}$

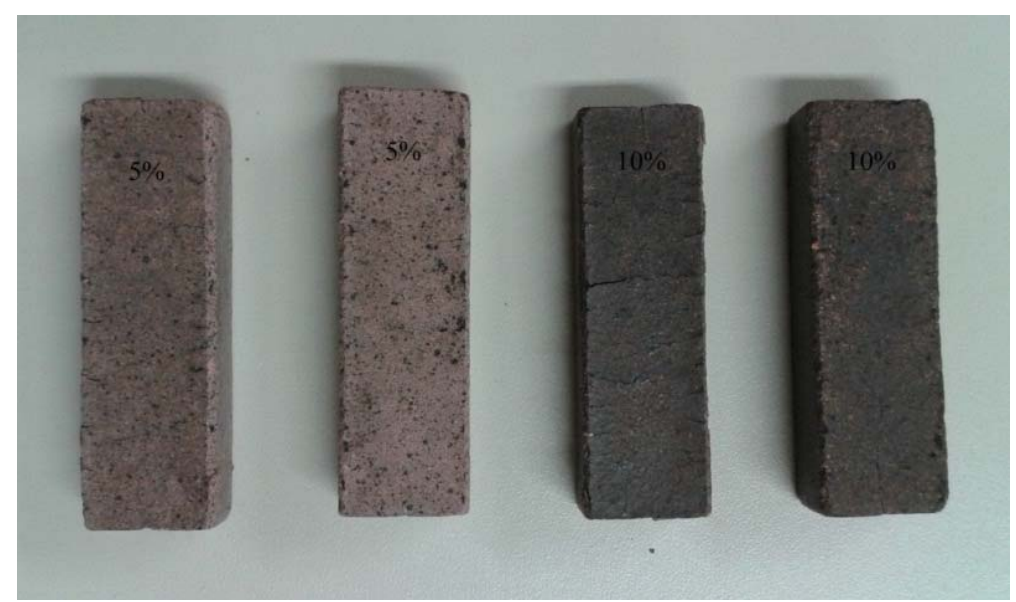

Figura 9. Corpos de prova depois da queima a $1000^{\circ} \mathrm{C}$

Pode-se perceber que quanto maior a adição de pó e maior a temperatura de queima mais escuro se tornou o corpo de prova cerâmico. A coloração de marrom a grafite provavelmente deve-se a presença de óxidos de ferro e manganês, como visto na análise química do pó.

Segundo Santos [3], a adição de resíduo de manganês tem o efeito de escurecer a peça cerâmica o que pode permitir a customização das cores dos produtos dentro de uma determinada faixa desejada.

\section{CONCLUSÃO}

- Maiores valores de adição de pó e temperatura provocaram uma maior densificação do corpo cerâmico, sendo que a temperatura foi a variável que mais influenciou nos resultados de densidade.

- $\mathrm{Na}$ retração linear de secagem o ideal seria trabalhar com valores intermediários de pressão e adição de pó, para garantir resultados nulos.

- Na retração linear de queima, maiores valores de adição de pó e temperatura provocaram uma maior retração, sendo que a temperatura foi a variável que mais influenciou nos resultados e a pressão a menos significativa.

- A condição ótima para fabricação dos corpos cerâmicos seria uma adição de pó de $10 \%$, temperatura de queima de $1000^{\circ} \mathrm{C}$ e pressão com valores entre $20 \mathrm{MPa}$ e 40MPa. 


\section{Agradecimentos}

Os autores agradecem à Universidade Federal de Ouro Preto e à Fundação Gorceix.

\section{REFERÊNCIAS}

1 Schuller D, Bianchi EC, Aguiar PR, Simões RP. Influência de defeitos e diferentes processos de fabricação nas propriedades mecânicas finais das cerâmicas. $\mathrm{V}$ Congresso Brasileiro De Engenharia De Fabricação. 2009.

2 Bragança SR, Berfmann CP. Microestrutura e propriedades de porcelanas. Cerâmica. 2004; Vol. 50: 291-299.

3 Santos OC. Formulação de bloco intertravado cerâmico com adição de resíduos urbanos e industriais [tese]. Rio Grande do Norte: Universidade Federal do Rio Grande do Norte; 2013.

4 Rebmann MS, Salvetti AR. Influência de densidade a seco e temperatura de queima sobre as características dos corpos cerâmicos. Anais de congresso, 2000.

5 Paixão LCC, Yoshimura HN, Espinosa DCR, Tenorio JAS. Efeito da incorporação de lodo de ETA contendo alto teor de ferro em cerâmica argilosa. Cerâmica. 2008; 54: 6376.

6 Oliveira LHM. Caracterização do pó de despoieramento de uma usina de produção de ferro ligas de manganês [monografia]. Ouro Preto: Universidade Federal de Ouro Preto; 2014.

7 Ferreira WL. Adição de resíduos do setor mínero-metalúrgico na fabricação de tijolos solo-cal [dissertação]. Ouro Preto: Universidade Federal de Ouro Preto; 2013.

8 Oliveira APN. Tecnologia de Fabricação de Revestimentos Cerâmicos. Cerâmica Industrial. 2000; 5(6);

9 Batista VR, Nascimento JJS, Lima AGB. Secagem e retração volumétrica de tijolos cerâmicos maciços e vazados: uma investigação teórica e experimental. Revista Matéria. 2009; 14(4): 1088-1100.

10 Acchar W. Materiais Cerâmicos: Caracterização e aplicações. Natal: EDUFRN; Editora da UFRN; 2006.

11 Castro CG. Estudo do aproveitamento de rejeitos do beneficiamento do manganês pela indústria cerâmica [dissertação]. Ouro Preto: Universidade Federal de Ouro Preto; 2011. 